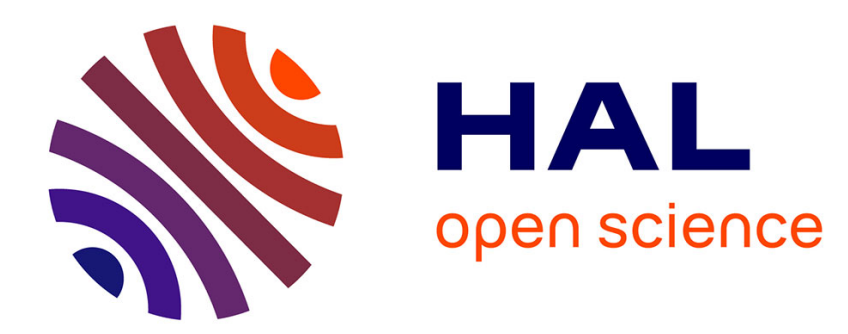

\title{
DIPOLE ORIENTATION EFFECTS IN RARE-EARTH DOPED CdF2
}

\author{
R. Capelletti, F. Fermi, E. Okuno
}

\section{To cite this version:}

R. Capelletti, F. Fermi, E. Okuno. DIPOLE ORIENTATION EFFECTS IN RARE-EARTH DOPED CdF2. Journal de Physique Colloques, 1973, 34 (C9), pp.C9-69-C9-74. 10.1051/jphyscol:1973910 . jpa-00215385

\section{HAL Id: jpa-00215385 https://hal.science/jpa-00215385}

Submitted on 1 Jan 1973

HAL is a multi-disciplinary open access archive for the deposit and dissemination of scientific research documents, whether they are published or not. The documents may come from teaching and research institutions in France or abroad, or from public or private research centers.
L'archive ouverte pluridisciplinaire HAL, est destinée au dépôt et à la diffusion de documents scientifiques de niveau recherche, publiés ou non, émanant des établissements d'enseignement et de recherche français ou étrangers, des laboratoires publics ou privés. 


\title{
DIPOLE ORIENTATION EFFECTS IN RARE-EARTH DOPED $\mathrm{CdF}_{2}$
}

\author{
R. CAPELlETtI, F. FERMI and E. OKUNO $(*)$ \\ Gruppo Nazionale di Struttura della Materia del CNR, Parma, Italy \\ Istituto di Fisica dell'Università, 43100 Parma, Italy
}

\begin{abstract}
Résumé. - De nombreuses expériences ITC effectuées entre 80 et $200 \mathrm{~K}$ montrent sans équivoque les dipôles en second voisin, terre rare-fluor interstitiel dans $\mathrm{CdF}_{2}$ : Eu. L'énergie d'activation d'orientation $(0,40 \mathrm{eV})$ et le facteur préexponentiel $\left(\tau_{0}=10^{-12} \mathrm{~s}\right)$ sont évalués pour le pic ITC principal $\left(T_{\mathrm{M}}=152,5 \mathrm{~K}\right.$ ) et comparés aux paramètres obtenus dans les fluorures de strontium et de calcium dopés à l'europium. D'autres pics à 168 et $186 \mathrm{~K}$ sont aussi analysés.

Une étude parallèle sur $\mathrm{CdF}_{2}: \mathrm{Gd}$ montre que des effets électroniques ne sont pas négligeables et peuvent masquer des relaxations dipolaires. La différence entre Eu et Gd est discutée.
\end{abstract}

\begin{abstract}
A number of experiences carried out by means of ITC technique in the temperature range 80-200 $\mathrm{K}$ shows unequivocally that $\mathrm{n}$. n. Rare Earth-Fluorine Interstitial (RE-FI) dipole reorientation occurs in $\mathrm{CdF}_{2}:$ Eu, resolving the puzzle of the lack of this kind of relaxation in trivalent ions doped $\mathrm{CdF}_{2}$, as reported by previous authors. The activation energy for orientation $(\varepsilon=0.40 \mathrm{eV})$ and the preexponential factor $\left(\tau_{0}=10^{-12} \mathrm{~s}\right)$ are evaluated for the principal ITC peak $\left(T_{\mathrm{X}}=152.5 \mathrm{~K}\right)$ discussed and compared with the analogous parameters in Eu doped Ca and $\mathrm{Sr}$ fluorides. Other ITC peaks at 168 and $186 \mathrm{~K}$ are also analyzed.

A parallel study on $\mathrm{CdF}_{2}: \mathrm{Gd}$ shows that electronic effects are not negligible and can mask dipolar relaxations. The difference between $\mathrm{Eu}$ and $\mathrm{Gd}$ is discussed.
\end{abstract}

1. Introduction. - An increasing interest has been devoted recently to the study of dielectric and ionic transport properties of $\mathrm{CdF}_{2}$ pure and doped with monovalent and trivalent cations [1]-[4]. This interest was stimulated since the discovery of the conversion of $\mathrm{CdF}_{2}$ containing small amounts of trivalent ionic impurities from an insulator to a $n$-type semiconductor when heated in $\mathrm{Cd}$ vapor at $500{ }^{\circ} \mathrm{C}$ [5], [6]. In alkali doped $\mathrm{CdF}_{2}$, between 20-300 K, Kunze and Müller [1] found ionic thermoconductivity (ITC) [7] peaks due to reorientation of monovalent cation-fluorine vacancy dipoles in the low temperature range, and peaks due to space charge in the high temperature range. Surprisingly, in the rare earth doped samples no signal due to orientation of trivalent cation-fluorine interstitial (RE-FI) dipoles was detected. This feature outlines a striking difference between $\mathrm{CaF}_{2}$ and $\mathrm{CdF}_{2}$, since it is well known that rare earth doped $\mathrm{CaF}_{2}$ shows two well defined ITC peaks [8], [9] due to orientation of RE-FI dipoles. The lower temperature peak $(\sim 50 \mathrm{~K})$ is assigned by Stott and Crawford to the presence of fluorine interstitial in the next-nearestneighbour-position (trigonal symmetry). It seems however unlikely that jumps from one $n$ nn position can take place [10]. The higher temperature peak $(\sim 140 \mathrm{~K})$, ascribed to the presence of fluorine interstitial in the nearest-neighbour position (tetragonal

(*) On leave from Instituto de Fisica da Universidade de S. Paulo and Instituto de Energia Atomica, S. Pilulo, Brasil. symmetry), was examined more extensively [8], [9], [11]-[13]. This unexplained difference between RE doped $\mathrm{CaF}_{2}$ and $\mathrm{CdF}_{2}$ stimulated us to undertake the study of $\mathrm{CdF}_{2}$ doped with $\mathrm{Eu}^{3+}$ and $\mathrm{Gd}^{3+}$ by means of ITC technique.

2. Experimental details. - The samples were obtained from Optovac Inc. (pure $\mathrm{CdF}_{2}$ ). Some samples were kindly supplied by Dr. J. B. Feldmann (pure $\mathrm{CdF}_{2}$ and $\mathrm{Gd}$ doped $\mathrm{CdF}_{2}$ ) and by Dr. E. Loh (Eu doped $\left.\mathrm{CdF}_{2}\right)$. Thin slices were obtained by cutting single crystal ingots with a wire saw: the specinen surfaces were then polished by lapping. The thickness of samples ranged from 0.6 to $1 \mathrm{~mm}$, the area from 0.5 to $1.2 \mathrm{~cm}^{2}$

The samples were submitted to different etching procedures : 1) they were washed in ammonia solution then rinsed in methanol as suggested by Kunze and Müller [1] ;2) they were simply rinsed in acetone or ethanol.

The ITC measurements were obtained : 1) by putting the bare sample within electrodes;2) by coatıng the sample surfaces with colloidal graphite in order to improve the contact with electrodes : 3 ) by interposing two thin teflon foils between electrodes and sample in order to obtain blocking electrodes.

The ITC measurements were performed by the usual procedure [7]. The crystal slab was polarized in a static electric field (ranging from $10^{2}$ to $2 \times 10^{+} \mathrm{V} / \mathrm{cm}$ ) for the polarizing time $t_{p}$, at the temperature $r_{p}$ and 
then cooled down to the temperature $T_{\mathrm{f}}$, where the field was switched off. The polarizing time $t_{\mathrm{p}}$ ranged from 1 to $15 \mathrm{~min}$ : it is worthwhile noticing that generally $t_{\mathrm{p}}$ was $3 \mathrm{~min}$. During the above steps the dipoles become polarized at saturation and remain orientated in the same configuration obtained at the polarization temperature, because at low temperature the relaxation time is practically infinite. The crystal was then warmed up at nearly constant rate : the dipole relaxation time for orientation gets shorter and shorter and dipoles lose their preferred orientation, giving rise to a depolarization current. This was detected at linearly increasing temperature by a vibrating reed electrometer (Cary 31V) and recorded by Speedomax. The apparatus can measure currents as low as $10^{-16} \mathrm{~A}$. The reproducibility of measurements was within $2 \%$.

Two cryostats with different performances were employed: the former, with vertical identical shaped aluminium electrodes, assured the minimum temperature gradient through the sample; in the latter, with horizontal gold electrodes, the top one can be put in contact with liquid nitrogen in order to get a very fast quenching of the sample.

3. Results. - 3.1 General features of ITC PEAKS IN $\mathrm{CdF}_{2}$ : Eu AND $\mathrm{CdF}_{2}:$ Gd. - In our ITC measurements we were concerned with the temperature range between $80 \mathrm{~K}$ and $200 \mathrm{~K}$, neglecting on purpose the higher temperature region where the complex space charge or charge displacement peaks occur, as reported by previous authors [1]-[3]. Moreover in the above low temperature range ITC peaks due to reorientation of interstitial fluorine-rare earth dipoles are expected to occur for the sake of analogy with $\mathrm{CaF}_{2}$ rare-earth doped [8], [9], [1 1 ]-[13].

Figure 1 shows the ITC spectrum of an Eu doped $\mathrm{CdF}_{2}$ slice between teflon blocking electrodes (see section 2).

Curves $a$ ) and $b$ ) were obtained by polarizing the sample at $T_{a}=165 \mathrm{~K}$ and $T_{b}=175 \mathrm{~K}$ respectively for $3 \mathrm{~min}$ with $500 \mathrm{~V}$. Two peaks can be resolved at $152.5 \mathrm{~K}$ and $168 \mathrm{~K}$. It is worthwhile noticing that another peak appears at $186 \mathrm{~K}$, but it will not be considered extensively in this work. This complex structure resembles that found by Wagner and Mascarenhas in $\mathrm{SrF}_{2}$ : Eu [14].

Figure 2 shows the ITC spectrum of Gd doped $\mathrm{CdF}_{2}$, with graphite improved contacts, for different polarization temperatures $T_{\mathrm{p}, \mathrm{n}}$ (indicated by arrows) and $T_{f, n}$ (see section 2 ). The polarization temperature range for each ITC run is shown by horizontal lines. The polarization field and polarization time $t_{\mathrm{p}}$ were $160 \mathrm{~V} / \mathrm{cm}$ and $3 \mathrm{~min}$ respectively.

It turns out, from figure 2 , that the proper choice of $T_{\mathrm{p}}$ and $T_{\mathrm{f}}$ allows to distinguish at least three peaks at 118,143 and $160 \mathrm{~K}$. By comparison of figures 1 and 2, ITC peaks both in $\mathrm{Gd}$ and in Eu doped $\mathrm{CdF}$, appear in the same temperature region where $\mathrm{RE}-\mathrm{FI}$ dipoles reorientation peaks occur in $\mathrm{CaF}_{2}$ and $\mathrm{SrF}_{2}$ as shown by the vertical arrows at the top of figures.

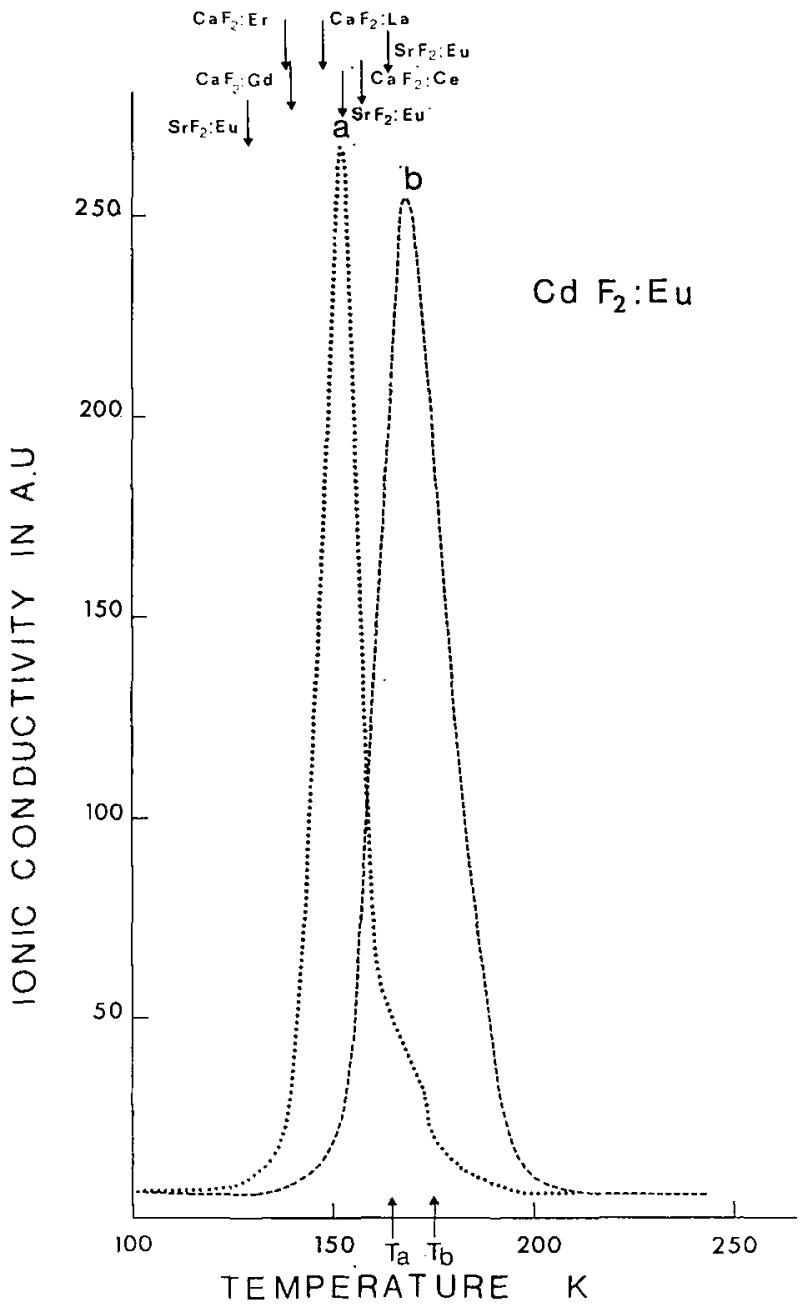

Fig. 1. - Ionic thermoconductivity in $\mathrm{CdF}_{2}:$ Eu with blocking electrodes. Polarization temperature was $T_{a t}=165 \mathrm{~K}$ for curve $a ; T_{b}=175 \mathrm{~K}$ for curve $b$. The arrows on the top show the peak temperatures of ITC band due to RE-FI dipoles in rareearth doped $\mathrm{CaF}_{2}$ and $\mathrm{SrF}_{2}$.

3.2 EFFECT OF $T_{p}, t_{p}$ AND CONTACTS ON THE POSITION AND INTENSITY OF ITC PEAKS IN $\mathrm{CdF}_{2}:$ Eu AND IN $\mathrm{CdF}_{2}$ : Gd. - We must emphasize that the position, at which various peaks occur in $\mathrm{Gd}$ and $\mathrm{Eu}$ doped $\mathrm{CdF}_{2}$, does not depend on the polarization temperature $T_{\mathrm{p}}$ and polarization time $t_{\mathrm{n}}$ : the slight peak shifts among different curves shown in figure 2 must be obviously ascribed to the mutual overlapping of the neighbour bands, whose intensity changes on the polarization temperature $T_{\mathrm{p}}$. Moreover the different kinds of contacts described in the previous section do not affect the position of peaks. However the use of blocking electrodes affects the intensity of depolarization peaks due to $\mathrm{Eu}$ and $\mathrm{Gd}$ in surprisingly different way. In $\mathrm{Gd}$ doped $\mathrm{CdF}_{2}$ the depolarization current signals $I$ and $I_{0}$ of samples with and without blocking electrodes respectively are strikingly different and thoir ratio is quite far from the expected value [15]:

$$
I=I_{0} \frac{\varepsilon_{\mathrm{t}} d_{\mathrm{c}}}{\varepsilon_{\mathrm{t}} d_{\mathrm{c}}+\varepsilon_{\mathrm{i}} d_{\mathrm{l}}}
$$




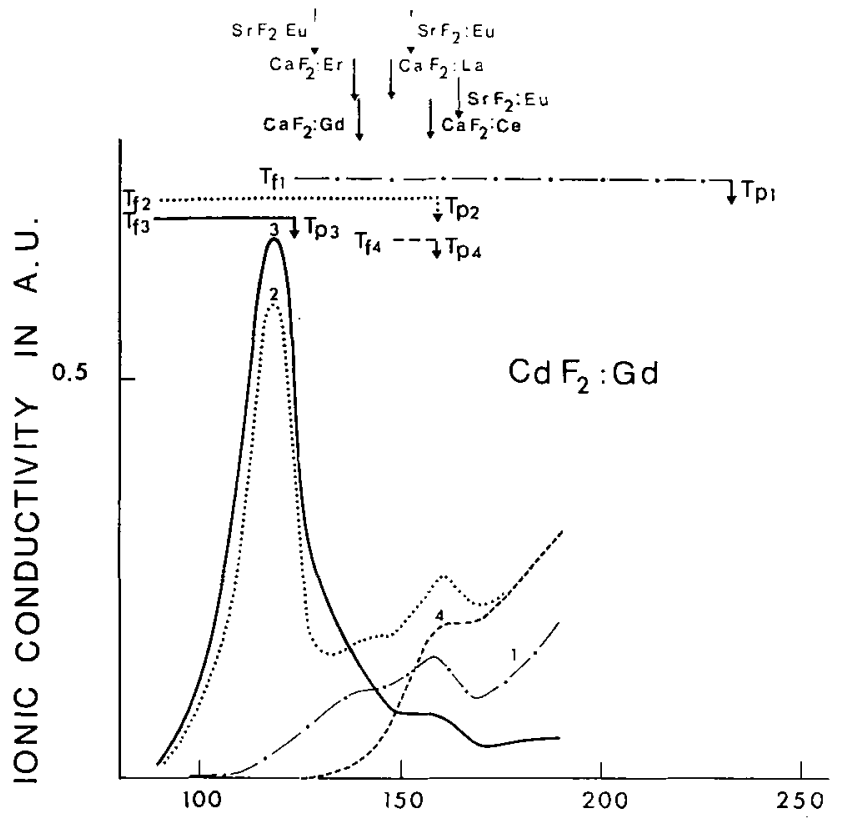

TEMPERATURE $\mathrm{K}$

FIG. 2. - Ionic thermoconductivity in $\mathrm{CdF}_{2}: \mathrm{Gd}$ with graphite improved contacts. Polarization temperatures $T_{\mathrm{n}, \mathrm{n}}$ and temperatures at which the electric field was turned off $T_{p, n}$ are shown for each curve $n$. The arrows on the top show the peak temperatures of ITC band due to RE-FI dipoles in rare-earth doped $\mathrm{CaF}_{2}$ and $\mathrm{SrF}_{2}$.

where $\varepsilon_{\mathrm{t}}=2$ and $\varepsilon_{\mathrm{c}}=9$ [16] are the static dielectric constants of teflon and $\mathrm{CdF}_{2}$ respectively, $d_{\mathrm{c}}$ and $d_{t} / 2$ are the thicknesses of the sample and of the teflon layer respectively. The expected value of $I / I_{0}$ in $\mathrm{CdF}_{2}: \mathrm{Gd}$ was $\approx 0.3$, while the measured one was less than $10^{-2}$. This striking difference turns out chiefly for the peak at $118 \mathrm{~K}$, while is less astonishing for the other peaks. On the contrary, in the case of $\mathrm{CdF}_{2}$ : Eu the expected and measured values of $I / I_{0}$ were in a reasonable agreement.

3.3 Comparison with pure $\mathrm{CdF}_{2}$. - It must be noticed that in the same temperature range ITC spectrum of pure $\mathrm{CdF}_{2}$ does not show any peak which can be identified with those appearing in $\mathrm{Gd}$ and Eu doped $\mathrm{CdF}_{2}$. Actually a weak ITC band occurs in pure $\mathrm{CdF}_{2}$ in the temperature range 120 $200 \mathrm{~K}$ (see Fig. 3) but with striking differences with respect to $\mathrm{Eu}$ and $\mathrm{Gd}$ doped $\mathrm{CdF}_{2}$ as explained in the following.

1) The band is very small, i. e. nearly 300-400 times weaker than the peak in $\mathrm{Gd}$ and Eu doped $\mathrm{CdF}_{2}$ respectively (in all the cases, bare samples were introduced between electrodes, see section 2).

2) The temperature at which the maximum of ITC peak occurs in pure $\mathrm{CdF}_{2}$ does depend on the polarization temperature $T_{\mathrm{p}}$ and polarization time $t_{\mathrm{p}}$. In figure 3 curves 1,2 and 4 were obtained by polarizing the sample with $E_{\mathrm{p}}=8330 \mathrm{~V} / \mathrm{cm}$ at $T_{\mathrm{p}}=151 \mathrm{~K}$ for $t_{\mathrm{p}}=3,15$ and 1 min respectively,

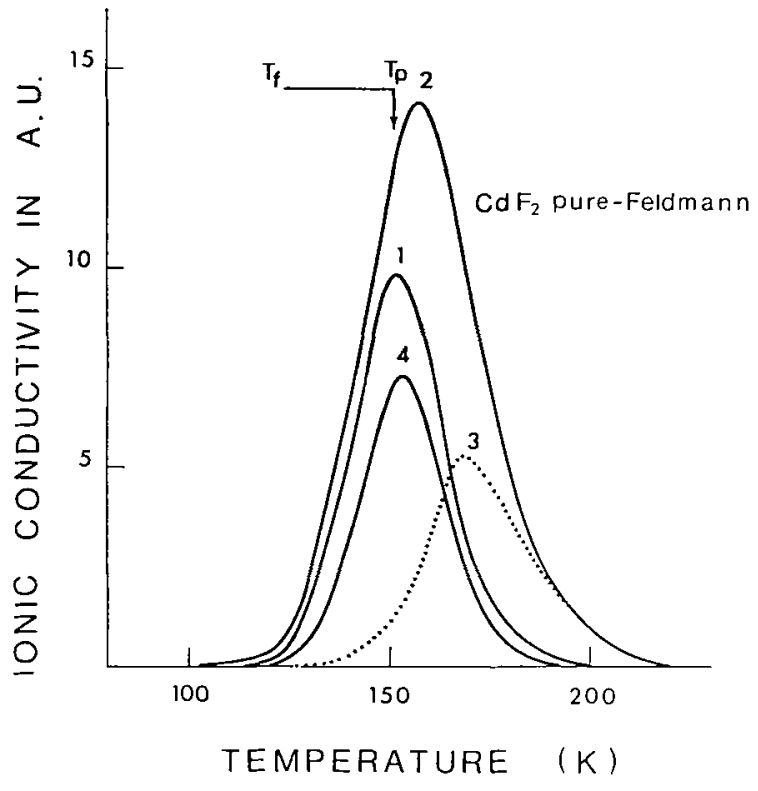

FIG. 3. - Ionic thermoconductivity in pure $\mathrm{CdF}_{2}$. The polarization temperature range (shown on the top) and the polatization field $E_{\mathrm{p}}=8330 \mathrm{~V} / \mathrm{cm}$ are the same for all curves; polarization time $t_{\mathrm{p}}$ is 3 and $1 \mathrm{~min}$ for curves 1 and 4 respectively; $15 \mathrm{~min}$ for curves 2 and 3 . Curve 3 is obtained after a partial discharge to $156 \mathrm{~K}$

down to $T_{\mathrm{f}}=123 \mathrm{~K}$. The observed peak temperature shift cannot be at all ascribed to differences in the heating rate during ITC detection. In fact, the heating rate $\beta$, which was $0.125 \mathrm{~K} / \mathrm{s}$ in the region where ITC band occurs, showed changes within $1.5 \%$ through the three runs. Also the band intensity is strongly affected by $t_{\mathrm{p}}$. Curve 3 is still more meaningful : $T_{\mathrm{p}}, t_{\mathrm{p}}, T_{\mathrm{f}}$ and $E_{\mathrm{p}}$ were the same of curve 2, so the polarization $P$, which remains frozen in when the field $E_{\mathrm{p}}$ is turned off at $T_{\mathrm{f}}$, must be the same given by the area under curve 2 . The sample was then warmed up, but the heating was stopped at $T=156 \mathrm{~K}$ (a temperature slightly lower than the peak temperature of curve 2): during this step only a fraction of polarization $P$ is released. The sample was cooled down again to $T_{\mathrm{f}}$ and finally warmed up in order to release the residual frozen in polarization completely: curve 3 gives the depolarization current versus temperature detected during this step. The peak is still more shifted to higher temperature. The above results suggest that the ITC spectum in the tempeperature range $120-200 \mathrm{~K}$ in pure $\mathrm{CdF}_{2}$ is not given by a single peak, but is due to the thermal induced disordering of "dipoles » with different relaxation times, possibly with a continuous relaxation time distribution (or to the thermal induced release of carriers from traps with energy depths distributed continuously).

It must be recalled that Kunze and Müller [1] really found an ITC peak in the range $180-220 \mathrm{~K}$ in $\mathrm{Na}$ doped $\mathrm{CdF}_{2}$, that they ascribed to charge carrier redisplacement (CD hand). However the 
features shown by our band in pure $\mathrm{CdF}_{2}$ are not consistent with those of the Kunze and Müller band. So we rule out the possibility that our band is due to the presence of sodium traces. Nevertheless we looked for the low temperature band due to the reorientation of $\mathrm{Na}$ ion-fluorine vacancy dipoles found by the above authors at $103.5 \mathrm{~K}$. We actually found a very weak band peaked at $106 \mathrm{~K}$ which we ascribed to residual $\mathrm{Na}$ impurities, due to their relatively high solubility in $\mathrm{CdF}_{2}$ (as NaF) [17]. Furthermore the low intensity of the band allowed us to conclude that our samples are quite pure. Incidentally, here we report the activation energy for orientation of sodium-anion vacancy dipoles measured by using the methods [17] described in details later. The activation energy was found to be $0.34 \pm 0.02 \mathrm{eV}$ in good agreement with Kunze and Müller value of $0.31 \mathrm{eV}$.

As a concluding remark to this section, we can say that the peaks detected in $\mathrm{CdF}_{2}: \mathrm{Gd}$ and $\mathrm{CdF}_{2}$ : $\mathrm{Eu}$ in the temperature $120-200 \mathrm{~K}$ are really different from ITC bands detected in the same range in pure and $\mathrm{Na}$ doped $\mathrm{CdF}_{2}$.

3. $4 \mathrm{CdF}_{2}: \mathrm{Eu}:$ LINEARITY AND ACTIVATION ENERGY MEASUREMENTS. - The intensity of $a$ ) and $b$ ) peaks was studied versus the intensity of the polarizing voltage $V_{\mathrm{p}}$ for Eu doped $\mathrm{CdF}_{2}$ : the results are shown in figure 4 . Linear relationship between peak intensity and $V_{\mathrm{p}}$ holds for both peaks, at least up to $1500 \mathrm{~V}$, as expected for non interacting dipoles.

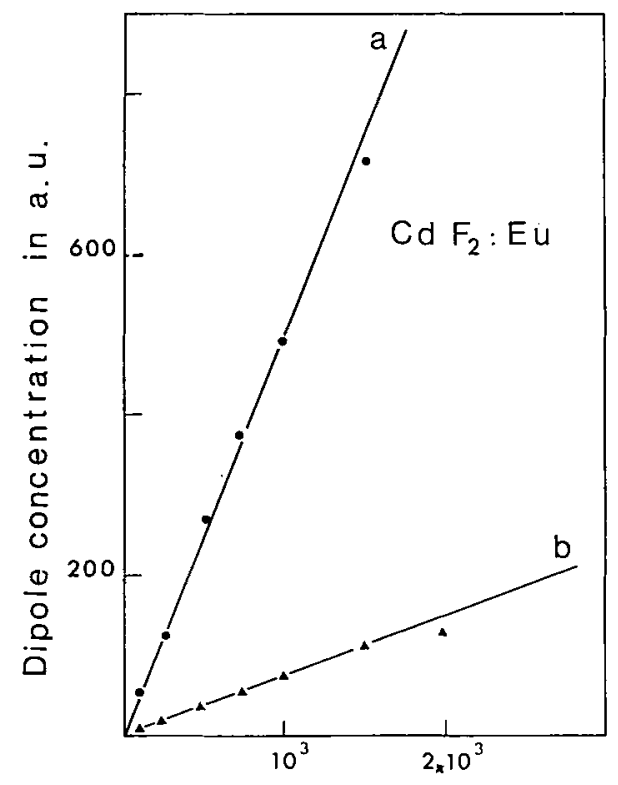

Polarization voltage in volts

FIG. 4. - The dipole concentrations related to ITC peaks $a$ and $b$ of figure 1 are plotted versus polarizing voltage $V_{\mathrm{n}}$ for $\mathrm{CdF}_{2}$ : Eu sample with blocking electrodes.

This result stimulated us to investigate if the dipole disorientation kinetics could be obtained from the shape of at least one of the peaks. If the dipole disorientation occurs through a first order monomolecular kinetics, the depolarization current density $j(T)$ is described by [7]:

$$
\begin{aligned}
j(T)=\frac{N p^{2} E_{\mathrm{p}} \alpha}{k T_{\mathrm{p}}}\left(\tau_{0} \exp \frac{\varepsilon}{k T}\right)^{-1} \times \\
\quad \times \exp \left[-\int_{0}^{T}\left(\beta \tau_{0} \exp \frac{\varepsilon}{k T^{\prime}}\right)^{-1}\right] \mathrm{d} T^{\prime}
\end{aligned}
$$

where $N$ is the dipole concentration, $p$ the dipole moment, $\alpha$ a geometrical factor, $T_{\mathrm{p}}$ and $E_{\mathrm{p}}$ are the polarization temperature and field, $\tau_{0} \exp \varepsilon / k T=\tau(T)$ is the dipole relaxation time, $\tau_{0}$ the pre-exponential factor, $\varepsilon$ the activation energy for dipole orientation and finally $\beta$ the heating rate. If the above hypothesis holds, the activation energy $\varepsilon$ can be obtained in two ways, i. e. :

$$
\ln \frac{\int_{T}^{\infty} j\left(T^{\prime}\right) \mathrm{d} T^{\prime}}{j(T)}=\ln \tau_{0}+\frac{\varepsilon}{k T}
$$

and, for $T \ll T_{\mathrm{M}}$

$$
\ln j(T) \simeq \text { const. }-\frac{\varepsilon}{k T}
$$

where $T_{\mathrm{M}}$ is the temperature at which the peak maximum occurs. A logarithmic plot of the left hand side expressions in (3) and (4) versus $(T)^{-1}$ gives two specular straight lines, i. e. with the same slope absolute value, but opposite sign. In figure 5 the

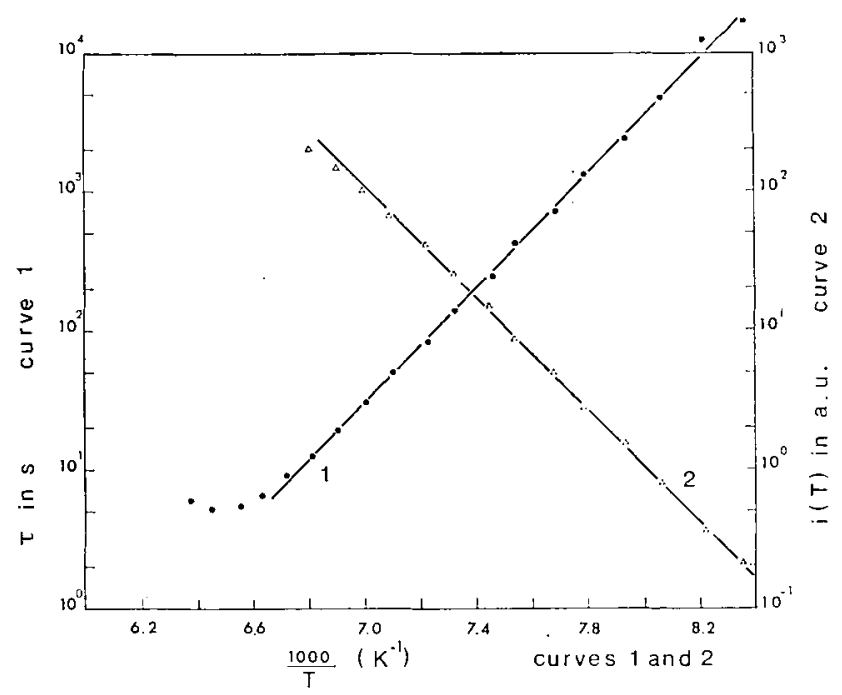

FIG. 5. $-\mathrm{CdF}_{2}:$ Eu with blocking electrodes : determination of orientational activation energy for peak $a$. Curve 1 : logarithmic plot of relaxation time $\tau$ versus $1000 / T$ as obtained from experimental data by using formula (3). Curve 2 : logarithmic plot of current density versus $1000 / T$ following formula (4).

experimentally determined values of the left hand side of eq. (3) (curve 1) and (4) (curve 2) were plotted versus $1000 / T$, for instance for band $a$ ). Obviously care was taken to avoid the overlapping of side peaks, 
by properly choosing $T_{\mathrm{p}}$ and $T_{\mathrm{f}}$ and by using the partial discharge technique [7]. Two straight lines can be really identified in figure 5 ; from the absolute value of the slope, the orientation activation energy turns out to be $0.40 \mathrm{eV}$. From eq. (3) the pre-exponential factor too can be calculated as $\tau_{0} \simeq 10^{-12} \mathrm{~s}$. These values are in fine agreement with those found for RE-FI dipoles in $\mathrm{CaF}_{2}$ [8], [9], [11], [14], as discussed in detail in section 4.

It must be noticed that such an unequivocal behaviour cannot be ascertained for peak $b$ due to the unavoidable overlapping of the neighbour peaks. Incidentally it must be reported that the linearity checks carried out for band appearing at $186 \mathrm{~K}$ did not give satisfactory results. However the relative activation energy $\varepsilon$ could be evaluated easily: $\varepsilon$ was found to be $0.40 \mathrm{eV}$ and $\tau_{0} \sim 10^{-11} \mathrm{~s}$.

$3.5 \mathrm{CdF}_{2}$ : $\mathrm{Gd}$. - The situation in $\mathrm{Gd}$ doped samples is much more complex, because, even if the ITC peaks are, unambiguously, due to $\mathrm{Gd}$, however their intensities are not linear function of $E_{\mathrm{p}}$ and activation energy determination becomes difficult due to the important overlapping of the nearest bands. An attempt to evaluate $\varepsilon$ for band peaked at $118 \mathrm{~K}$ gave very low values (about $0.1 \mathrm{eV}$ ), which are too far from the value $0.4 \mathrm{eV}$ typical of RE-FI dipoles in $\mathrm{CaF}_{2}$ and $\mathrm{CdF}_{2}$ : Eu.

It is worthwhile noticing that preliminary $\mathrm{dc}$ measurements (i. e. measurements of the dc current which flows through the sample when electric field $E$ is on) performed at constant temperature $\left(T_{\mathrm{p}}=162 \mathrm{~K}\right)$ showed the same current versus applied field functional dependence that was found for the thermal induced depolarization current (measured at the peak for the ITC band at $118 \mathrm{~K}$ ), when the polarization temperature $T_{\mathrm{p}}$ was still $162 \mathrm{~K}$. The functional field dependence of current $I$ was of the Poole-Frenkel type [18] in both cases, i. e.

$$
I \propto \exp \left(\frac{B E^{1 / 2}}{k T_{\mathrm{p}}}\right)
$$

where $B$ is constant. The formula usually describes the Poole-Frenkel carrier detrapping from a single localized donor level, when Coulombic well is assumed for the donor potential. The same field dependence of thermocurrent and dc current suggests that both can be related to the same mechanism and moreover effects due to the presence of electrons cannot be ruled out.

4. Concluding remarks. - From the above results, it turns out that the principal features of band $a$ ) in $\mathrm{CdF}_{2}$ : Eu can be summarized as follows :

1) The peak is really due to the presence of europium :

2) The band is not due at all to charges injected from electrodes, because it is developed also with teflon blocking electrodes;
3) The peak temperature does not depend both on $T_{\mathrm{p}}$ and $t_{\mathrm{p}}$;

4) The peak temperature is in the region where the second RE-FI dipole reorientation band occurs in $\mathrm{CaF}_{2}$ doped with various trivalent cations and in $\mathrm{SrF}_{2}$ : Eu [14];

5) The polarization induced is a linear function of the polarizing field $E_{\mathrm{p}}$, as predicted by the Langevin formula for uniform bulk polarization due to noninteracting dipoles, in the approximation $p E_{\mathrm{p}} \ll k T_{\mathrm{p}}$;

6) The band shape is nicely described by formula (2), which holds for non-interacting dipoles, whose disorientation occurs through a first order monomolecular kinetics ;

7) The activation energy for dipole orientation obtained in the above frame is $0.40 \mathrm{eV}$, in fine agreement with those of the homologous band in $\mathrm{CaF}_{2}$.

The discrepancy from the values of activation energy found for Eu peaks in $\mathrm{SrF}_{2}$ [14] $(\approx 0.3 \mathrm{eV})$ can be understood by taking into account that the $\mathrm{Sr}^{++}$ ionic radius $(1.38 \AA)$ is appreciably different from $\mathrm{Ca}^{++}$and $\mathrm{Cd}^{++}$ionic radii $(1.26 \AA$ and $1.21 \AA$ respectively) in fluorides [19]. The activation energies, pre-exponential factors and cation radii are summarized in table $\mathrm{I}$ for $\mathrm{Ca}, \mathrm{Cd}$ and $\mathrm{Sr}$ fluorides. The

TABLE I

Motion parameters for ITC peaks in the temperature range $120-190 \mathrm{~K}$ in $\mathrm{Ca}, \mathrm{Cd}$ and $\mathrm{Sr}$ fluorides doped with europium.

\begin{tabular}{|c|c|c|c|c|}
\hline Matrix & $\begin{array}{l}\text { Activation } \\
\text { energy }(\mathrm{eV})\end{array}$ & $\begin{array}{l}\text { Pre- } \\
\text { exponential } \\
\text { factor } \\
\tau_{0}(\mathrm{~s})\end{array}$ & $\begin{array}{l}\text { Refe- } \\
\text { rence }\end{array}$ & $\begin{array}{c}\text { Divalent } \\
\text { cation } \\
\text { radius } \\
\AA[19]\end{array}$ \\
\hline $\mathrm{CaF}_{2}$ & 0.40 & $1 \times 10^{-13}$ & [14] & 1.26 \\
\hline $\mathrm{CdF}_{2}$ & 0.40 & $1 \times 10^{-12}$ & & 1.21 \\
\hline & $\begin{array}{c}\text { (peak at } 152.5 \mathrm{~K} \text { ) } \\
0.40 \\
\text { (peak at } 186 \mathrm{~K} \text { ) }\end{array}$ & $1 \times 10^{-11}$ & $\begin{array}{l}\text { present } \\
\text { work }\end{array}$ & \\
\hline $\mathrm{SrF}_{2}$ & $\begin{array}{l}0.26 \\
0.28 \\
0.33\end{array}$ & $\begin{array}{r}2 \times 10^{-9} \\
5 \times 10^{-8} \\
2.5 \times 10^{-9}\end{array}$ & [14] & 1.39 \\
\hline
\end{tabular}

frequency factor $1 / \tau_{0}=10^{12} \mathrm{~s}^{-1}$, obtained for the peak at $152.5 \mathrm{~K}$, is realistic if compared with the vibrational frequencies in $\mathrm{CdF}_{2}$ lattice. In fact, by using data on restrahlen absorption wavenumber and on static and high frequency dielectric constants, reported by Eisenberger and Pershan [16], one can evaluate $\omega_{\mathrm{LO}}$ (longitudinal optical frequency) $\approx 7.6 \times 10^{12} \mathrm{~s}^{-1}$ and $\omega_{\text {To }}$ (transverse optical frequency) $\approx 4 \times 10^{12} \mathrm{~s}^{-1}$, both higher than $1 / \tau_{0}$.

The whole phenomenology of $152.5 \mathrm{~K}$ ITC peak in $\mathrm{CdF}_{2}$ : Eu fits nicely to the picture of the other europium doped fluorides and more generally of $\mathrm{CaF}_{2}$ doped with trivalent rare earths. The attribution of ITC peak at $152.5 \mathrm{~K}$ to the disorientation of substitutional trivalent europium-fluorine interstitial dipoles in $\mathrm{CdF}_{2}$ seems quite reasonable, in this way 
resolving the puzzle of lack [1] of these dipolar defects in a crystalline structure so close to that of $\mathrm{CaF}_{2}$.

However from our results in $\mathrm{CdF}_{2}: \mathrm{Gd}$, the formation of rare earth-fluorine interstitial dipoles does not look as a common feature of RE doped $\mathrm{CdF}_{2}$. Even if the strong peaks we found in $\mathrm{CdF}_{2}: \mathrm{Gd}$, in the range $100-180 \mathrm{~K}$, must be unequivocally attributed to the presence of $\mathrm{Gd}$, however, their properties are not consistent with those of a uniform bulk polarization of a system of non-interacting dipoles. The practical suppression of depolarization current signal, caused by blocking electrodes, suggests that injection of carriers from electrodes can take place, in absence of blocking electrodes. Moreover the relation (5) which seems to hold at $162 \mathrm{~K}$ both for thermal induced depolarization current and for $\mathrm{dc}$ current, suggests that electronic effects could be present, possibly due to a weak non-stoichiometricity of the sample, and can overlap or mask the weak reorientation signals due to RE-FI dipoles (we recall here that we obtained small signals with blocking electrodes). It is still puzzling why Eu gives RE-FI dipole reorientation signal and $\mathrm{Gd}$ does not. ESR and ENDOR measurements in $\mathrm{CdF}_{2}$ : Gd [20] showed that the predominant ESR spectrum arises from substitutional $\mathrm{Gd}^{3+}$ in cubic sites and no chargecompensating $\mathrm{F}^{-}$ion is present within $7 \AA$ from $\mathrm{Gd}^{3+}$, while non-cubic sites, due also to the presence of unwanted paramagnetic impurities, are less than $10 \%$. This supports that $\mathrm{Gd}^{3+}$ in tetragonal symmetry (that expected for RE-FI dipoles) represents only a small fraction of $\mathrm{Gd}^{3+}$ and in part can account for the difficulty in detecting unambiguous ITC signals.
This difficulty seems to hold also for other trivalent ions, for instance $\mathrm{La}$ and $\mathrm{In}$, as shown by Kunze and Müller [1]. Kessler [3] ascribed this fact to the use of blocking electrodes, but our results in $\mathrm{CdF}_{2}: \mathrm{Eu}$ showed that the detection of RE-FI dipole reorientation peak when it is really present is not limited at all by the use of blocking electrodes. It is worthwhile noticing that a thermal depolarization current peak was found by Kessler [3] in $\mathrm{CdF}_{2}$ : Y at $129 \mathrm{~K}$, which the author attributed to $\mathrm{Y}^{3+}-\mathrm{FI}$ dipole reorientation. However, in our opinion, there is a little shadow of doubt that it can be unambiguously due to dipole relaxation because its presence was not checked by using blocking electrodes and, furthermore, its activation energy was found to be only $0.205 \mathrm{eV}$ which is far from the $0.4 \mathrm{eV}$ value reported for $\mathrm{RE}$ doped $\mathrm{CaF}_{2}$. In this way overiapping electronic effects can affect the dipole relaxation detection, as in our $\mathrm{CdF}_{2}$ : $\mathrm{Gd}$. At present it looks that only Eu gives undoubtedly RE-FI dipole reorientation ITC peaks in $\mathrm{CdF}_{2}$ : consequently it would be worthwhile to analyze the hehaviour of other trivalent ions in $\mathrm{CdF}_{2}$ in order to understand why RE-FI pairs are not a common feature of all trivalent ions as in $\mathrm{CaF}_{2}$.

5. Acknowledgments. - The authors express their gratitude to Dr. E. Loh and to Dr. J. B. Feldmann which supplied some of the samples. They are also grateful to Prof. R. Fieschi for stimulating discussions ; one of them (E. O.) wishes to thank the Fundação de Amparo à Pesquisa do Estado de S. Paulo (FAPESP) for financial support.

\section{References}

[1] Kunze, I., Müller, P., Phys. Stat. Sol. (a) 13 (1972) 197.

[2] Kessler, A., Caffyn, J. E., J. Phys. C 5 (1972) 1134.

[3] Kessler, A., J. Phys. C 6 (1973) 1594.

[4] Tan, Y. T., Kramp, D., J. Chem. Phys. 53 (1970) 3691.

[5] Kingsley, J. D., Prener, J., Phys. Rev. Lett. 8 (1962) 315.

[6] Prener, J. S., Kingsley, J. D., J. Chem. Phys. 38 (1963) 667.

[7] BuccI, C. A., Fieschi, R., GuidI, G., Phys. Rev. 148 (1966) 816.

[8] Stott, J. P., Crawford, J. H. Jr., Phys. Rev. Lett. 26 (1971) 384.

[9] Stott, J. P., Crawford, J. H. Jr., Phys. Rev. B 4 (1971) 668.

[10] Franklin, A. D., Crissman, J., J. Phys. C 4 (1971) 239.

[11] Royce, B. S. H., Mascarenhas, S., Phys. Rev. Lett. 24 (1970) 98.

[12] Stiefbold, D. R., Huggins, R. A., J. Sol. St. Chem. 5 (1972) 15.
[13] Stiefbold, D. R., Huggins, R. A., J. Chem. Phys. 56 (1972) 3173.

[14] Wagner, J., Mascarenhas, S., Electrets, Charge Storage and Transport in Dielectrics, ed. by M. M. Perlman, p. 54, 1973.

[15] Takamatsu, T., Fukada, E., Ibid., p. 128.

[16] Eisenderger, P., Pershan, P. S., Phys. Rev. 167 (1968) 292.

[17] Rubenstein, M., Banks, E., J. Electrochem. Soc. 106 (1959) 404.

[18] Hill, R. M., Phil. Mag. 23 (1971) 205.

[19] Shannon, R. D., Prewitt, C. T., Acta Cryst. B 25 (1969) 925.

[20] Borcherts, R. H., Cole, T., Horn, T., J. Chem. Phys. 49 (1968) 4880. 